\title{
One Busy Day! A Critical Analysis of New Faculty Orientation Programs
}

Michael T. Miller (Corresponding author)

College of Education and Health Professions, University of Arkansas, USA

Email: mtmille@uark.edu

Received: $21 / 04 / 2021$

Accepted: 10/06/2021

Published: 01/07/2021

Volume: 2 Issue: 4

How to cite this paper: Miller, M. T. (2021). One Busy Day! A Critical Analysis of New Faculty Orientation Programs. Journal of Practical Studies in Education, 2(4), 5-10

DOI: https://doi.org/10.46809/jpse.v2i4.27

Copyright (C) by author(s) and Global Talent Academy Ltd. This work is licensed under the Creative Commons Attribution International License (CC BY 4.0).

http://creativecommons.org/licenses/by/4.0/

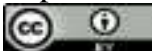

\begin{abstract}
New faculty orientation programs can serve as an important introduction to an academic community. They can create expectations, provide exposure to technical assistance, and welcome faculty members to new communities. The current study explored new faculty orientation programs, cataloging their activities to identify the most common practices in researchcentered universities. Findings revealed a strong reliance on one-day programs that often host a variety of speakers from different offices, yet they rarely were found to have any sort of outcomes based approach to their design. To be effective, these programs should possibly incorporate longer activities that might last an entire semester or academic year. Further, these programs might include virtual as well as in-person opportunities to learn about the institution, the students they serve, and the offices and other tools that the institution provides to help faculty be successful. Further study on the effectiveness of different models is also recommended.
\end{abstract}

Keywords: College Faculty, Faculty Effectiveness, Faculty Expectations, New Faculty Orientation, Teaching Effectiveness

\section{Introduction}

Colleges and universities are increasingly specific in interpreting who they are and who they want to be, and as a result, what they expect from their faculty members. This is seen in how institutions 'modify' their faculty working titles to have individuals who focus specifically on teaching or specifically on research. Titles such as "Professor of Practice" or "Teaching Professor" reflect this movement. A subsequent challenge to the institution is in helping define the role and expectations of faculty members, and this extends beyond the initial hiring process where jobs descriptions and essential functions are typically used to clarify what an employee is expected to do.

Many institutions make use of a new faculty orientation program to help clarify for both the institution and the faculty member what is expected of them, and to aid in their transition to the faculty life at the institution. These programs are also designed to aid in promoting faculty retention and the acculturation of new faculty into the campus and local community (Miller \& Nadler, 2001), and developing a strategic orientation to such programming has been noted as a priority for some institutions (Horton \& Hintz, 2002).

Historically, new faculty orientation programs have struggled to define their role and purpose, and this dialogue is well over 50 years old (Norris, 1958). Watson and Flournoy (1970) noted that at the time of their writing, most new faculty orientation programs were inconsequential, and Neyens (1977) wrote "generally, the scope of activities is limited and consists of formal speeches by both faculty and administrators" (p. 114). Such perspectives on relatively poor or ineffective new 
employee orientations are not limited to higher education, and have been reported to permeate much of the corporate workplace as well (Acevedo \& Yancey, 2011).

There is little debate or contending the realization that an institution is only as strong as its faculty, and orientation and development programs are critical in this regard. Those who work in the field of orientation, whether for new students or employees, have argued that the initial orientation experience sets the tone for the individual and is highly important for creating a culture of support, morale, retention, and productivity. Although orientation programs may differ for different types of employees, new faculty orientation programs are unique for several reasons. First, faculty members typically have a deep content specialization and training, yet have little training in activity for which they frequently are hired to conduct, aka, teaching (Alsop, 2018). Second, faculty specializations differ greatly, as do their teaching styles and expectations, making broad conversations unwieldy, as, for example, poets sit next to engineers during orientation. Third, faculty are often hired as a result of a national search, meaning that they must navigate the introduction to a new community along with a new job. The result of these challenges, along with the timing of often being held just prior to the start of an academic term, results in a wide range of new faculty orientation programs that vary in their designs and effectiveness.

Considering the importance of faculty members in institutional performance, and the observations that new employee and faculty orientation programs have been less than effective, the current study was designed to explore what new faculty orientation programs include and how they are structured. Specific attention is given to the introductory programs that orient a new faculty member to a particular institution, and through content analysis, describe what types of messages might be conveyed to new faculty members.

The college faculty role is critical to the success of higher education, as these individuals deliver not only the instruction needed for student success, but also provide the research skills to enhance knowledge through research and development activities (Kezar \& Maxey, 2014). Faculty members also, through their involvement on campus, create a sense of community that can make decisions, plan in a meaningful way for the future, and engage in building the campus community that encourages student development. In short, faculty members are the human capital that creates value in the academy, and their success is the success of the entire institution (Umbach \& Wawrzynski, 2004). Because faculty members are so critical to institutional behavior, their development is of paramount concern to senior institutional leaders.

\section{Background of the Study}

Although higher education leaders verbally support and acknowledge the importance of faculty and their development, the landscape or practice of faculty development is uneven and inconsistent (Lancaster, Stein, MacLean, Amburgh, \& Persky, 2014). Some institutions have aggressively assembled programs to help their faculty be successful in teaching and research, and some have done very little in this regard. Most programs that are in place fall into one of several categories, including stand-alone programming, continuous improvement, and integrated programming.

Stand-alone faculty development programs are those that consist of singular programs that are typically not related. They might be event-focused, meaning, a single instance program focused on some aspect of improving the faculty member's work. These programs might be a teaching or grant writing workshop. Academic leaders will occasionally make use of needs or interest surveys to identify topics to be presented on, and they are timed based on some situational criteria, such when the most faculty can attend, when a grant proposal might be due, or when courses have to be developed.

Continuous improvement faculty development programs are those that build on previous knowledge and are scheduled at regular intervals to respond to faculty member needs. These are programs rather than singular events and can also be developed and created based on needs and interest assessments. Many of these programs increasingly use technology to bring together individual programs and continue discussions, learning, and interactions.

Integrated programs are those that use real-time outcomes from activities and integrate them into developmental programs. Examples would be related to research training, where the developmental activity results in some tangible output, and the success or failure of that output is fed back into the system to assist the faculty member. In teaching, this might be instruction about how to integrate some technological strategy into a class lecture, and the faculty member then integrates it and reports back about how it has worked or not worked.

This variety of faculty development programming reflects an evolving perspective on investing in faculty members and demonstrates that institutions, through their efforts, do indeed care for their faculty and how they perform. New faculty orientation programs similarly are a reflection of this value, and in their structure and measurement of outcomes can indicate the level of commitment an institution has toward faculty members.

Orientation programs, for employees broadly, are considered to be important to creating a particular climate and culture in the workplace, although there is some recognition that most of these programs lack sufficient depth, sophistication, or perspective to fully integrate employees into their workplace (Acevedo \& Yancey, 2011). Programs that would be considered 'event-based,' are perhaps the best example of the potential limitations of new faculty orientation. By focusing all resources and experiences into a one-time program, the institution seems to be acknowledging the importance of orientation, but also demonstrating either a commitment to tradition ("we have always done it this way") or lack of real concern for what the orientation program is capable of accomplishing. There have been subsequent arguments that new faculty orientation programs should subsequently be learner-focused, and that such programs might be more effective in not only transitioning faculty to their new institution, but in increasing morale and preventing turnover (Cullen \& Harris, 2008). 
Higher education's reliance on limited programming is not restricted to faculty members, however, as institutions have developed and rely on similar types of programs for new students. Whether referred to as 'new student orientation' or 'welcome week,' activities take on a presentation of materials and resources without measuring the effectiveness of this work. Some institutions have responded by developing semester long first-year-experience courses, recognizing that to develop an appreciation for a culture and an institution's resources might take more than a day. For students, the Council for the Advancement of Standards (CAS) developed standards for what should be included in new student orientation programs, and these guidelines have become to be recognized as the criteria for what is necessary for new college students to be integrated into their campus communities. CAS does not have standards for new faculty orientation programs, although much of what they advocate for mirrors the needs of new faculty members when they arrive on campus.

As there is a strong recognition that orientation programs can be powerful (Bauer, 2010), illustrating the need to better understand what higher education institutions are doing with new faculty orientation. By identifying what is currently being done, best practices might be identified that can help other institutions perform at a higher level or ideas might be generated to assist institutions in re-developing a program that might produce better results for their campus.

\section{Research Methods}

As a descriptive analysis of new faculty orientation programs, the study made use of materials presented on college and university web-sites about new faculty orientation programs. To classify the description, institutions that were classified as High or Very High Research Activity by the Carnegie Foundation were selected for inclusion in the study. These two classifications of institutions reflect the dual mission of teaching and research as expectations of faculty members. The 2019 listing of these types of institutions included 185 different institutions, however, removing institutions in US territories and unique institutions (medical only institutions, senior only institutions, research only institutions) resulted in a listing of 182 unique universities.

Once the listing of 182 universities was developed, each institution's website was consulted to identify programs and agendas for new faculty orientation programs. There were 34 universities that did not include any information for 2019 or 2018, and as a result, were not included in the analysis. As a note, however, three of these institutions required institutionally provided passwords to view the new faculty orientation agenda and materials, and these materials were not publicly available. There were 25 universities that did not provide 2019 information, but did for 2018, and those materials were used in the analysis, accepting the assumption that there was not a significant change in programming between years. Once these materials and agendas were assembled, they were critically examined for categories and frequencies of each were identified. A sample of 25 sets of materials was reviewed by another scholar to check for category development and classification.

This process of content analysis was deemed to be reliable and valid to the extent that the materials presented publicly were accurate representations of the work of the institution.

\section{Findings}

The majority of new faculty orientation programs were events that last 4-6 hours $(\mathrm{n}=53 ; 36 \%)$, although an near equal number $(\mathrm{n}=44 ; 30 \%)$ lasted $6-8$ hours, and as shown in Table 1 , the fewest programs $(\mathrm{n}=24 ; 16 \%)$ lasted more than 8 hours. These programs were typically one-day workshops $(n=112 ; 76 \%)$, although several lasted more than two days $(n=6 ; 4 \%)$ and nearly a fifth of the programs included an on-line component $(n=39 ; 19 \%)$. As a parenthetic note, most of the on-line modules included in the new faculty orientations were required or strongly encouraged topical trainings, such as diversity/inclusive teaching programs $(n=6)$, sexual harassment awareness training $(n=4)$, and safety and awareness of working with those under the age of $18(n=4)$. Two institutions also included an on-line training program to explain and provide exposure to the state's history and the unique cultural heritage that students might bring to campus with them.

Also shown in Table 1, nearly half of the new faculty orientations $(n=72 ; 49 \%)$ included optional or self-choice break-out sessions. Sample break-out sessions included using the institution's learning management system, preparing for the first day of class, benefits sessions (health, dental, vision, retirement), introduction to grant writing services, etc. Several institutions organized their new faculty orientation programs around a particular theme $(n=8 ; 5 \%)$ such as 'students first,' and several organized their programs around different teaching strategies $(n=11 ; 7 \%)$ such as service learning, project based learning, or technology-enhanced teaching.

Table 1. Length and Structure of New Faculty Orientation $\mathrm{N}=148$

\begin{tabular}{lll}
\hline Characteristic & $\mathrm{n}$ & $\%$ \\
\hline & & \\
Under 4 hours & 27 & $18 \%$ \\
4-6 hours & 53 & 36 \\
$6-8$ hours & 44 & 30
\end{tabular}


More than 8 hours

One-day workshop

Two-day workshop

More than two-day

Online component

Thematically structured Teaching strategy focused Break out sessions

$\begin{array}{rr}112 & 76 \\ 30 & 20 \\ 6 & 4 \\ 29 & 19\end{array}$

8

11
16

76

20

19

Activities were identified on the agendas and supporting materials for each new faculty orientation program and a count of each activity was developed and is reported in Table 2, although only items or activities that were identified on at least five agendas/materials were included in the list. As shown in Table 2, the most common activity was a welcome to the new faculty from the provost or someone on the provost's staff $(n=101 ; 68 \%)$, followed by some form of social reception or formal dinner $(n=93 ; 63 \%)$, and a material presentation of some format about human resource benefits $(n=89$; $60 \%)$. Although there were at least ten different activities that were recorded at only one institution (such as a spouse and partner's association introduction and a faculty book club), the least common activities with at least five institutions offering the sessions were: welcome from the alumni association $(n=17 ; 11 \%)$, life in the community introduction $(n=16 ; 11 \%)$, a student panel discussion $(n=10 ; 7 \%)$, and a presentation on the state and/or regional characteristics $(n=9 ; 6 \%)$.

Also included in Table 2 is the indication that faculty senates welcomed and introduced themselves and their work at 68 different institutions $(46 \%)$, which was slightly more common than the institution's presidents/chancellor's making an introduction $(n=66 ; 45 \%)$. Over 50 institutions $(n=51 ; 34 \%)$ also had a welcome from the athletic department, although many of those presentations included discussions about how the new faculty members would go about purchasing season football or basketball tickets at a special rate.

Table 2. Frequency of New Faculty Orientation Activities $\mathrm{N}=148$

\begin{tabular}{|c|c|c|}
\hline Activity & Frequency & $\%$ \\
\hline Provost welcome & 101 & $68 \%$ \\
\hline Social reception/dinner & 93 & 63 \\
\hline Human Resources/Benefits Presentation & 89 & 60 \\
\hline Institutional mission/planning & 82 & \\
\hline Faculty discussion panel & 77 & 52 \\
\hline Research office services & 74 & 50 \\
\hline Faculty Senate/Governance Presentation & 68 & 46 \\
\hline President welcome & 66 & \\
\hline Faculty identification card & 56 & 38 \\
\hline Athletics welcome/address & 51 & 34 \\
\hline Institutional history & 27 & \\
\hline Campus values & 23 & 15 \\
\hline Alumni Association welcome & 17 & \\
\hline Life in the Community Presentation & 16 & 11 \\
\hline Student discussion panel & 10 & 7 \\
\hline State/region characteristics & 9 & \\
\hline
\end{tabular}

In addition to events held during the new faculty orientation day agenda, the additional materials provided some insights as to how an institution approaches the intake of new faculty members. A majority of institutions ( $\mathrm{n}=86$; 58\%) did not report anything in addition to the new faculty orientation day (or two-day program). In about a third of the institutions, as shown in Table 3, the orientation materials promoted, alluded to, or advertised monthly teaching improvement/strategy sessions ( $\mathrm{n}=55$; $37 \%)$, individual human resource or benefit counseling $(\mathrm{n}=48 ; 32 \%)$, and retirement (strategy) planning workshops ( $\mathrm{n}=44$; $30 \%)$. There were a host of other programs that were provided information on, such as teaching workshops ( $\mathrm{n}=39 ; 26 \%)$, grant writing workshops $(\mathrm{n}=19 ; 13 \%)$, formal mentoring programs $(\mathrm{n}=11 ; 7 \%)$, and two different online programs, one of which was similar to a new student orientation course but directed to faculty $(n=14 ; 9 \%)$, and one a one-time online program targeted at a compliance-related training $(n=7 ; 5 \%)$. 
Table 3. Additional materials: Extended New Faculty Orientation Activities $\mathrm{N}=148$

\begin{tabular}{|c|c|c|}
\hline Activity & Frequency & $\%$ \\
\hline Nothing beyond one-day meeting & 86 & $58 \%$ \\
\hline Monthly programs - teaching & 55 & \\
\hline Individual human resource benefit counseling & 48 & 32 \\
\hline Retirement planning workshop & 44 & 30 \\
\hline Teaching strategy workshop & 39 & \\
\hline Monthly programs - research & 32 & \\
\hline Monthly programs - unspecified & 26 & 18 \\
\hline Grant writing workshop & 19 & 13 \\
\hline Online support during the year & 14 & 9 \\
\hline Formal mentoring program & 11 & \\
\hline One-time online program & 7 & 5 \\
\hline
\end{tabular}

\section{Discussion and Conclusions}

The agendas and supporting materials reviewed in the current study reflect a tremendous amount of time, energy, and resources that are devote to building and implementing new faculty orientation programs. These programs, however, as Cullen and Harris (2008) suggested, seem to be based not on intentional outcomes, but perhaps rather on a series of activities. Cullen and Harris focused their attention primarily on faculty as learners, advocating for an outcomes-based approach to program offerings, suggesting that the key for senior academic leaders is that they become intentional in design these types of programs.

The broad range of topics covered in these programs suggest a diffused approach to orientation programs and that they generally lack a clear purpose or underlying rationale for their use. The argument can be made that they serve to introduce new faculty to their institutions and the people who they will work with, and that level of outcome is present, and perhaps reflective of a lower level of learning as reflected on Bloom's taxonomy (remembering or understanding). These types of activity-based orientations also did not appear to have action-oriented outcomes.

A philosophical approach to new faculty orientation that stresses introductions and an easing-in to a new community can be a good rationale for such programs, but if that is truly the desired outcome, then some of the program activities might be structured and prioritized differently. There might, for example, more attention placed on developing the interpersonal dynamics of new faculty members, much as new student orientation programs focus on building social support networks first, and technical knowledge second. The new faculty programs reviewed here seemed to lack a general understanding of what they were designed to accomplish.

A secondary philosophical approach to a new faculty orientation could be focused on skill or content instruction. Programs that present models of effective teaching or other high impact practices might be instructive and helpful to new faculty as they prepare to enter the classroom. And, the idea of providing instructional support or exposure to innovative ideas also presents the issue of the timing of new faculty orientation. Those programs that provided advice on how to design a syllabus, for example, presented to new faculty three days before the beginning of the semester, might well be too late for immediate impact.

New faculty orientation programs seem to be attempting to cover a great many purposes, and academic leaders might be well served to take a step back and reflect on the intended outcomes and purposes of new faculty orientation, and then design programs and experiences based on those outcomes. Additionally, with the growth of faculty title modifers, such as 'professor of practice,' 'clinical,' 'research,' or 'teaching professor,' orientation programs might be well served to develop different types of orientation outcomes for different types of appointed faculty. This could mean different types of orientation programs, or it might mean additional layers of programming or targeted programs for certain faculty based on their expected areas of work and needed professional development.

Orientation, as a one or two day workshop, at best can begin the process of integrating new faculty into their new communities, and they can be a powerful tool in doing such. They cannot, however, be a panacea for empowering new faculty to take on every task or fulfill every duty. Strategic new faculty orientation must be considered a process built over time, and the introductory sessions should serve as the beginning of a significant process of acculturation, and not just a welcome day. 


\section{References}

Acevedo, J. M., \& Yancey, G. B. (2011). Assessing new employee orientation programs. Journal of Workplace Learning, 23(5), 349-354.

Alsop, E. (2018, February 11). Who's teaching the teachers? Chronicle of Higher Education, retrieved online at chronicle.com/article/Who-s-Teaching-the-Teachers-/242488.

Bauer, T. N. (2010). Onboarding new employees: Maximizing success. Alexandria, VA: Society for Human Resource Management.

Cullen, R., \& Harris, M. (2008). Supporting new scholars: A learner-centered approach to new faculty orientation. Florida Journal of Educational Administration and Policy, 2(1), 17-28.

Horton, J. A., \& Hintz, S. S. (2002). The new faculty orientation and mentoring program: A strategic approach. Annandale, VA: Northern Virginia Community College (ERIC ED 482 193).

Kezar, A., \& Maxey, D. (2014). Faculty matter: So why doesn't everyone think so? Thought and Action, 30, 29-44

Lancaster, J. W., Stein, S. M., MacLean, L. G., Amburgh, J. V., \& Persky, A. M. (2014). Faculty development program models to advance teaching and learning within health science programs. American Journal of Pharmaceutical Education, 78(5), 99. Doi: 10.5688/ajpe78599

Miller, M. T., \& Nadler, D. P. (2001). Finding purpose in new faculty orientation: The education dean's perspective. Journal of Faculty Development, 18(2), 87-93.

Neyes, R. T. (1977). Faculty orientation programs in Illinois junior colleges. Improving College and University Teaching, 25(2), 114-116, 118.

Norris, S. (1958). A faculty look at its orientation program. The American Journal of Nursing, 58(1), 80-81.

Scott, W., Lemus, D., Knotts, G., \& Oh, J. (2016). Why learner-centered new faculty orientations matter: Organizational culture and faculty retention. Journal of Faculty Development, 30(1), 15-22.

Umbach, P. D., \& Wawrzynski, M. R. (2004). Faculty do matter: The role of college faculty in student learning and engagement. Paper presented at the Association for Institutional Research Annual Forum, Boston, MA.

Warton, G., \& Flournoy, D. M. (1970). Faculty orientation. Change in Higher Education, 2(1), 60. 